\title{
Quantitative model of enterprise financial risk management based on nonlinear differential equation
}

\author{
Hui Yang, \\ Department of Economic Management,Liaocheng University Dongchang College, \\ Liaocheng, 252000 \\ China \\ Guixian Tian*, \\ School of Business, Pingxiang University, \\ Pingxiang, 337000 \\ China \\ Yongchao Tao, \\ Institute of Marine Economics, Shandong Academy of Social Sciences, \\ Qingdao, 266000 \\ China \\ E-mail: 18663510797@163.com
}

Received: April 15, 2021. Revised: August 21, 2021. Accepted: September 3, 2021. Published: September 6, 2021.

\begin{abstract}
In order to accurately assess the financial risks of enterprises, a quantitative model of enterprise financial risk management based on nonlinear differential equations is designed. According to the hierarchical running track of enterprises, 30 evaluation indexes are selected, the index weights are determined, and the financial risk evaluation index system is constructed. Constructing allocation judgment matrix based on binary allocation scale value. Copula nonlinear differential equation is selected to comprehensively quantify the risk management of enterprise financial portfolio. Realize the quantitative model of enterprise financial risk management. The accuracy of the design model is verified by experiments. The results show that the upper quantile of the design model analysis is closer to the standard value, which is consistent with the actual situation and is effective.
\end{abstract}

Keywords-Corporate Financial Risk, Management Quantitative Model, Index System.

\section{INTRODUCTION}

$\mathrm{P}$ eople's evaluation of enterprises is at a relatively consistent evaluation benchmark in different periods, and with the evolution of history and the deepening of people's understanding of enterprise evaluation, this benchmark is constantly changing. Since the 19th century, corporate goals have undergone an evolution from maximizing profits and benefits to maximizing shareholder value. In the 1980 s, with the gradual improvement of the corporate governance system and the continuous development of the capital market, more and more enterprises have paid more and more attention to value creation. And rethink and adjust how to formulate and implement corporate goals that reflect value creation [1]. Whether in neoclassical financial theory or new institutional financial theory, the ultimate goal of an enterprise is to maximize the value of the enterprise, or the shareholder value. Companies cannot ignore long-term value creation for short-term benefits. When a country's per capita GDP (Gross Domestic Product) exceeds 1000 US dollars, society will enter a period of high disaster and risk occurrence. China's rapid economic growth is accompanied by a large number of natural disasters, accidents, and environmental and health emergencies, even these events. One of them happened, and the value impact on the enterprise will be irreparable. Therefore, in order to prevent these risks, enterprises must have good operating practices to deal with these risks.

In the 21st century, the economy is becoming increasingly global. Various economic factors are no longer as simple as those in the planned economy period, and their operation 
trajectory is basically difficult to predict. Without corresponding preventive measures, the value of enterprises will be exposed to various risk factors. As risk factors fluctuate, companies will also be threatened by bankruptcy all the time, which will have a considerable impact on corporate investment financing, daily operations and other decision-making aspects. At the same time, theoretical studies have shown that if a company uses a comprehensive quantitative model for financial risk management, it will have a value-added effect on the company.

In the literature [2], based on the fuzzy comprehensive index evaluation model, some scholars have further incorporated the externality index into the enterprise financial risk model, established the enterprise financial risk management model through the fuzzy comprehensive evaluation method, incorporated the fuzzy number and membership degree, effectively transformed the subjective index into the objective index with statistical effectiveness, and further adopted the risk data of $\mathrm{H}$ enterprises listed in A shares to prove the feasibility of the model. In the literature [3], some scholars used SPSS statistical software to screen the financial indicators of manufacturing companies by principal component analysis (PCA), and then used MATLAB software to optimize the parameters of support vector machine with the help of particle swarm optimization (PSO), and built a company financial risk early warning model based on PSO-LIBSVM model. In the literature [4], some scholars used AHP, Defining risk assessment objectives, screening risk assessment indicators, designing "risk contribution degree" indicators, constructing risk judgment matrix, prioritizing risk response, scientifically constructing characteristic risk assessment quantitative model, and improving the scientificity and accuracy of risk identification. When the traditional model analyzes the upper quantile, in order to analyze the weight of the financial risk index of the enterprise, the error is large, which will affect the accuracy of the model's assessment of enterprise asset risk. Therefore, this paper uses non-linear differential equations to analyze the weights of corporate financial risk indicators and design a new quantitative model for corporate financial risk management. According to the design of an enterprise financial risk comprehensive evaluation index system, the goal of each level of the enterprise is established as a trajectory evaluation index, and the weight of each index is obtained. In order to further improve the accuracy of index weight, the allocation type judgment matrix is constructed by using binary allocation scale value, and Copula nonlinear differential equation is selected to describe the abnormal property of single asset yield distribution and the complex relationship between different asset returns. Realize the comprehensive risk management of enterprise financial asset portfolio. Experiments to verify the effectiveness of corporate financial risk evaluation and determine the effectiveness of quantitative models for corporate financial risk management. The upper quantile of the method in this paper fluctuates around the standard value of 2.1500, which shows that the model designed in this paper has high precision in calculating the upper quantile, and also shows that the model established in this paper has high suitability for the financial risks of enterprises. Moreover, the model designed in this paper can accurately describe the risk level of enterprises, and has certain practicability.

\section{QUANTITATIVE MODEL OF ENTERPRISE FINANCIAL RISK} MANAGEMENT BASED ON NONLINEAR DIFFERENTIAL EQUATION

\section{A. Establish a comprehensive evaluation index system for corporate financial risks}

The maximization of enterprise value means that the value of the main stakeholders of the enterprise is balanced to maximize the value. The enterprise is a whole. The living environment of the company has undergone tremendous changes compared with the past. The internal and external environment of corporate value creation has changed. The development of information, the advancement of knowledge, and economic globalization all explain that the core competitiveness, sustainable development capabilities, human resources, corporate image, and customer satisfaction of enterprises are becoming increasingly important to the value of the enterprise function [5]. Therefore, in order to better manage corporate financial risks, effectively and timely identify corporate financial risks, grasp the status quo of corporate development as a whole, and make better predictions of corporate vision. It is necessary to establish an enterprise risk comprehensive evaluation index system from the perspective of the enterprise's overall situation (considering internal and external factors), with the goals of various levels of the enterprise as its trajectory, and assisting enterprise risk management and enterprise value maximization.

Before the traditional credit services of enterprises are conducted, the assets strength, scale, pledge guarantee, and operation of the enterprise are generally inspected and evaluated. And according to relevant national laws and regulations and the People's Bank of China's credit rating management guidance, based on the scientific forecast of the future development prospects of the company, the credit rating of an enterprise is achieved through the above aspects. However, when general banks lend to enterprises, they will simplify some related steps, are not transparent enough, and the relevant mortgage qualifications that they can provide to banks are very limited, so they cannot pass the bank's credit rating inspection, and banks cannot Providing loans makes it difficult for SMEs to solve the problem of shortage of funds. If small and medium-sized enterprises need to obtain liquid funds in a timely manner, banks need to reform their lending models, especially for small and medium-sized enterprises. At this time, the Internet financial financing model is presented to small and medium-sized enterprises in a new attitude [6]. This method is more beneficial to SMEs than the traditional credit method, because this model downplays the access control and financial analysis of SMEs in credit ratings. Instead of the original financial statement analysis through the control and analysis of the capital flow and logistics of SMEs, the company will no longer conduct a comprehensive evaluation of the company's 
past, present and future. Only crediting and lending for a single business, this process not only examines the enterprise itself, but also the objects of its transactions, so that credit risk can be effectively controlled during the lending process. Of course, in establishing an Internet financial financing credit evaluation system, combining the creditworthiness of small and medium-sized enterprises and the ability to repay loans, we will focus on examining the success rate of a single transaction, how much profit is made, and the ability to trade. Taking the above factors into consideration, the index system established is shown in Table I.

Table. I Evaluation indicators and their descriptions

\begin{tabular}{|c|c|c|c|}
\hline First level indicators & $\begin{array}{l}\text { Second level } \\
\text { indicators }\end{array}$ & Third level indicators & Description \\
\hline \multirow{15}{*}{$\begin{array}{l}\text { Applicant } \\
\text { qualification }\end{array}$} & \multirow{4}{*}{$\begin{array}{l}\text { Adaptive capacity of } \\
\text { an enterprise }\end{array}$} & $\begin{array}{l}\text { Adaptive capacity of an } \\
\text { enterprise } C_{1}\end{array}$ & $\begin{array}{l}\text { Education background, continuous operation years of } \\
\text { the manager in the pump industry }\end{array}$ \\
\hline & & $\begin{array}{l}\text { Quality of staff and } \\
\text { workers } C_{2}\end{array}$ & Professional technology, professional ethics \\
\hline & & Management quality $C_{3}$ & $\begin{array}{c}\text { Management system, property right structure and } \\
\text { internal supervision }\end{array}$ \\
\hline & & $\begin{array}{l}\text { Quality of financial } \\
\text { disclosure } C_{4}\end{array}$ & $\begin{array}{l}\text { Audit of financial statements and information } \\
\text { disclosure }\end{array}$ \\
\hline & Management ability & $\begin{array}{l}\text { Business turnover } \\
\text { capacity } C_{5}\end{array}$ & $\begin{array}{l}\text { sales revenue / (Average prepayment balance }+ \text { average } \\
\text { receivable balance }+ \text { average inventory balance })\end{array}$ \\
\hline & \multirow{2}{*}{ Profitability } & Sales profit margin $C_{6}$ & Sales profit / sales revenue \\
\hline & & Return on equity $C_{7}$ & Quick ratio \\
\hline & \multirow{5}{*}{ Solvency } & Liquidity ratio $C_{8}$ & Current assets - current liabilities \\
\hline & & Quick ratio $C_{9}$ & (Current assets-Stock) / current liabilities \\
\hline & & Asset liability ratio $C_{10}$ & Total liabilities / total assets \\
\hline & & $\begin{array}{l}\text { The ratio of cash flow to } \\
\text { current liabilities } C_{11}\end{array}$ & Operating capacity cash flow / current liabilities \\
\hline & & Interest cover $C_{12}$ & Profit before tax / interest expense \\
\hline & \multirow{3}{*}{$\begin{array}{l}\text { Development } \\
\text { potential }\end{array}$} & Sales growth rate $C_{13}$ & $\begin{array}{l}\text { (Current sales revenue - Sales revenue in the same } \\
\text { period of last year)/Sales revenue in the same period of } \\
\text { last year }\end{array}$ \\
\hline & & $\begin{array}{l}\text { Net profit growth } \\
\text { rate } C_{14}\end{array}$ & $\begin{array}{c}\text { (Net profit of the current period - Net profit of the same } \\
\text { period of last year)/Net profit of the same period of last } \\
\text { year }\end{array}$ \\
\hline & & $\begin{array}{l}\text { Growth rate of total } \\
\text { assets } C_{15}\end{array}$ & $\begin{array}{c}\text { (Total assets of the current period-Total assets in the } \\
\text { same period of last year) / Total assets in the same } \\
\text { period of last year }\end{array}$ \\
\hline \multirow{4}{*}{$\begin{array}{l}\text { Counterparty } \\
\text { qualification }\end{array}$} & Credit level & Credit level $C_{16}$ & Credit rating of the counterparty in the bank \\
\hline & $\begin{array}{c}\text { Industry } \\
\text { characteristics }\end{array}$ & Industry status $C_{17}$ & $\begin{array}{l}\text { Characteristics of industry concentration, monopoly } \\
\text { and cycle }\end{array}$ \\
\hline & Stress capacity & Sales profit margin $C_{18}$ & Sales profit / sales revenue \\
\hline & Solvency & Quick acting ratio $C_{19}$ & (current assets-Stock) / current liabilities \\
\hline
\end{tabular}

As can be seen from Table I, the evaluation index system mainly examines the following four aspects:

(1) Apply for lender qualifications. Including the company's development scale, operating conditions, profitability, debt repayment ability and future development potential, this qualification is mainly composed of selecting the main indicators in traditional business ratings.

(2) Counterparty qualifications. Including the development scale, operating status, profitability, debt repayment ability and future development potential of counterparties. This evaluation index is used to examine the qualifications of companies in the Internet financial business.
(3) Assets under financing. It includes two characteristics, the first one is the material characteristic and the second one is the accounts receivable characteristic. The status of assets under financing is an important part of the investigation. After the evaluation is completed, credit is granted to customers based on the results.

(4) Business operations. Including the development status of the industry, the transaction records and reputations of both parties, the probability of successful transactions, the amount of transaction profits, etc. [7]. The assessment of the status of Internet operations represents the bank's overall assessment of the success rate of a single transaction by an applicant. In fact, in 
this way, the bank can give a credit rating to a single transaction of the company from the development situation of the entire industry and the qualifications of the companies on both sides, which makes the bank's inspection of the credit-granting enterprise more comprehensive. Through a single transaction, the general amount is not large. Reducing the quality of assessment caused by information asymmetry caused by enterprises concealing information.

\section{B. Determine system indicator weights}

In the financial field, we need to evaluate the credit risk of Internet financial business of credit endorsers, and we need to conduct a careful analysis of the evaluation results. Under normal circumstances, we generally use Logistic regression to establish quantitative financial risk management models. However, the credit risk assessment of our internet financial business is not quite the same as the traditional credit assessment. As SMEs generally need funds urgently and most of them make loans for the first time, the bank's credit data for SME customers is incomplete, and a complete data storage and management system has not been established. However, in the current credit background of SMEs, a nonlinear differential equation needs to be selected to determine the index weights [8]. The fitting and solving of non-linear differential equations are more complicated, and it is generally difficult to achieve the global optimum. For continuous functions, it is difficult for any algorithm to obtain an absolute accurate solution, and any algorithm may efficiently obtain high precision solution, but it is impossible to efficiently find a high-precision solution for every problem. If an algorithm can find a solution with high accuracy in most cases, and its calculation amount is not large, then it can be considered as an effective algorithm. It should be noted that the indicators in the above indicator system are not all positive indicators, but also include inverse indicators and moderate indicators, which need to be handled appropriately.

When assigning different weights to different indicators, there are many comprehensive evaluation methods, such as analytic hierarchy process, factor analysis, data envelope analysis, fuzzy comprehensive evaluation, and so on. In order to ensure that the weights are as scientific and reasonable as possible, this paper adopts a more subjective direct weighting method for primary indicators with relatively few indicators and poor comparability among indicators. Several secondary indicators of comparability use a weighting method based on allocation judgments [9]. Corporate management, profitability, corporate finance and corporate environment are interconnected for an enterprise. To enhance the value of the enterprise, the four aspects must be coordinated and developed, neglecting any link, and no other link can be effective. The development of enterprises will face a crisis of survival. Therefore, this article believes that, in theory, the four should be given the same weight. However, considering the above index system, because of the difficulty of quantifying the indicators, the enterprise management and the enterprise environment do not include some relatively important indicators. Therefore, the weights given to the four are: $0.1,0.4,0.4,0.1$.
First determine the weight of enterprise management indicators. The high education and salary of managers are not a sufficient condition for a company to have a sound management system, but a supplementary condition. Changes in the quality of enterprise management can be reflected in the receivable turnover rate and inventory turnover Rate and other indicators, therefore, the weight of each indicator given to the enterprise management is:

$$
w_{1}=\left[\begin{array}{l}
0.1 \\
0.1 \\
0.4 \\
0.4
\end{array}\right]
$$

For the determination of corporate profitability indicators and other indicator weights, this part of the method of constructing weights is the allocation of a judgment matrix. The first step is to compare the importance of the evaluation objects, assign binary weights, and construct an allocation judgment matrix [10]. Le $\mathrm{t} c_{i j}$ be the "binary weight allocation" of the importance of the two weighting indicators $i$ and $j$. The criteria for the binary allocation of importance weight vectors are shown in Table II.

Table. II Criteria for binary allocation of importance weight vectors

\begin{tabular}{ccc}
\hline Meaning & The value of $c_{i j}$ & The value of $c_{j i}$ \\
\hline $\begin{array}{c}i \text { is as important as } \\
j\end{array}$ & 0.50 & 0.50 \\
$i$ is a little more \\
$\begin{array}{c}\text { important than } j \\
i \text { is significantly } \\
\text { more important } \\
\text { than } j\end{array}$ \\
$\quad \begin{array}{l}\quad \text { is more } \\
\text { important than } j \\
i \text { is more }\end{array}$
\end{tabular}

According to the criteria in Table II, the constructed allocation judgment matrix is as follows:

$C=\left[\begin{array}{ccccc}0.5 & 0.3 & 0.4 & 0.55 & 0.55 \\ 0.7 & 0.5 & 0.55 & 0.9 & 0.9 \\ 0.6 & 0.45 & 0.5 & 0.7 & 0.7 \\ 0.45 & 0.1 & 0.3 & 0.5 & 0.5 \\ 0.45 & 0.1 & 0.3 & 0.5 & 0.5\end{array}\right]$

The statistical weight vector $w$ is solved from the matrix C. There are two main methods for solving the weight vector. One is the approximate solution, and the other is the optimal solution. This paper uses the inverse method of the approximate solution. Non-linear data are more typical and representative [11]. The method of marginal distribution of individual asset risk factors uses parameter estimation. In order to improve the accuracy of subsequent calculations, the best method is to inverse the distribution matrix constructed above to obtain a new matrix: 


$D=\left[\begin{array}{ccccc}2 & 3.3333 & 2.5 & 1.1818 & 1.1818 \\ 1.4286 & 2 & 1.1818 & 1.1111 & 1.1111 \\ 1.6667 & 2.2222 & 2 & 1.4286 & 1.4286 \\ 2.2222 & 10 & 3.3333 & 2 & 2 \\ 2.2222 & 10 & 3.3333 & 2 & 2\end{array}\right]$

Calculate the rows and values $R_{i}(i=1,2, \ldots, 5)$ of the new matrix $D$ :

$R_{i}=\sum_{j=1}^{5} \frac{1}{c_{i j}}$

There are 5 degrees of freedom in the estimation model of the physical parameters of the nonlinear equations. However, when dealing with the nonlinear equations, these methods have strict requirements for the use conditions of the equations. Choosing a good initial point is not an easy task for many non-linear equations. Even if the initial point is found, if it is not selected properly, it may cause the iterative solution to fail to converge or converge to an invalid solution. Poorly behaved nonlinear equations may also have poor convergence effects [12-14]. After calculation, we get:

$$
R=\left[\begin{array}{l}
R_{1} \\
R_{2} \\
R_{3} \\
R_{4} \\
R_{5}
\end{array}\right]=\left[\begin{array}{c}
10.1969 \\
6.8326 \\
8.7461 \\
19.5555 \\
19.5555
\end{array}\right]
$$

The objective function of Equation (3) only considers the molar fractions of each component in each matrix, while the objective function of Equation (5) considers the molar fractions $n$ of key components of each output stream. The key components here refer to the main components of the matrix, where the corresponding absolute weights $T_{i}=\frac{1}{R_{i}-n}$ and the corresponding weights are:

$$
T=\left[\begin{array}{l}
T_{1} \\
T_{2} \\
T_{3} \\
T_{4} \\
T_{5}
\end{array}\right]=\left[\begin{array}{l}
0.1924 \\
0.5467 \\
0.2669 \\
0.0687 \\
0.0687
\end{array}\right]
$$

From this, you can also calculate the normalized weight $w_{2}$, and judge the relative importance of the weight of each financial indicator of the enterprise. The idea of the corporate profit target must first meet the various stakeholders of the enterprise (return on assets and return on net assets). Followed by the pursuit of higher operating profit and operating efficiency. Similarly, according to this method, weights are assigned to various indicators of corporate finance. This completes the determination of the system index weights.

\section{Choosing the right nonlinear differential equation}

Enterprise financial risk management needs to examine the different risks faced by a single asset in the enterprise. These risk forms are diverse and interrelated, cross, and infiltrate, and work together on corporate finance. They have a superimposing and magnifying effect on the integrated risks facing corporate finance. Therefore, the risks caused by the combined action of different types of risk factors are essentially different from those driven by a single type of risk factor. The method of quantifying corporate financial risk by introducing nonlinear differential equations has gradually matured $[15,16]$. The application of nonlinear differential equations to the integrated risk measurement of asset portfolios has two advantages:

(1) Can describe the non-normal nature of the distribution of the rate of return of a single asset, that is, the characteristics of "peak and thick tail".

(2) Complex interrelationships between different asset returns can be described. There are many types of nonlinear differential equations. The two-dimensional equations selected in this paper are Copula equations, which are defined as:

$C_{G a}^{\rho}(u ; \rho)=\Phi_{\rho}\left(\Phi^{-1}\left(u_{1}\right), \ldots, \Phi^{-1}\left(u_{n}\right)\right)$

Among them, $\Phi_{\rho}$ represents a multidimensional normal distribution, $\Phi$ is a standard normal distribution, and $\Phi^{-1}\left(u_{n}\right)$ is an inverse function of the standard normal distribution. According to the characteristics of the linear and non-linear functions commonly used in the statistical analysis of corporate financial data, the equation we choose can be non-linear to the known 30 variables, and be measured against the standard deviation, the sum of the remaining squares, and the size of the coefficient of determination [17]. The effect of the curve to find the optimal equation describing the relationship of the variables.

The advantage of the traditional model is that its convergence speed is faster, but at the same time, this method has a large degree of dependence on the initial point, which makes this method have certain disadvantages. For intuitive understanding, scatter plots and contour plots are used to describe the distribution characteristics of the above equations. The scatter plot is shown in Fig. 1.

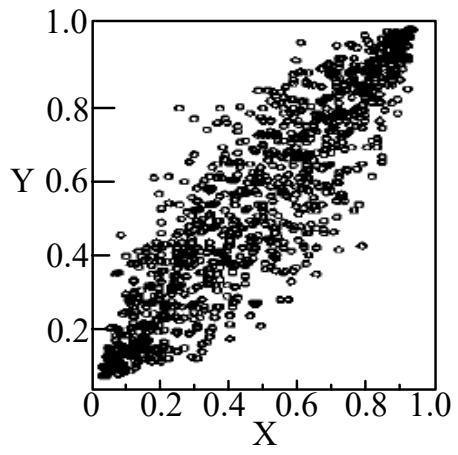

Fig. 1 Scatter plot of selected nonlinear differential equations

The value of $\rho$ is 0.9 . As can be seen from Fig. 1, the upper and lower tails of the scatter plot are symmetrical and relatively concentrated at the center. The shrinkage algorithm used for fitting nonlinear equations is a direct search algorithm that combines the contraction and expansion of the search space alternately. Initial trials on FIST data failed to achieve a global optimum for all data in all situations. This aspect shows the 
difficulty of fitting nonlinear equations, and it also shows that the original algorithm programs (mainly the feedback system among them) must be improved. In the fitting experiments on these and other data, the feedback parameters are continuously improved and made perfect.

According to the scatter plots of the selected nonlinear differential equations, contour plots similar to annual rings are drawn using contour plots in matlab, and it is tested that according to the continuous change of the parameter alpha of the clayton, the contours of the distribution function tend to be oval Rectangle with gradually sharp edges and corners, as shown in Fig. 2.

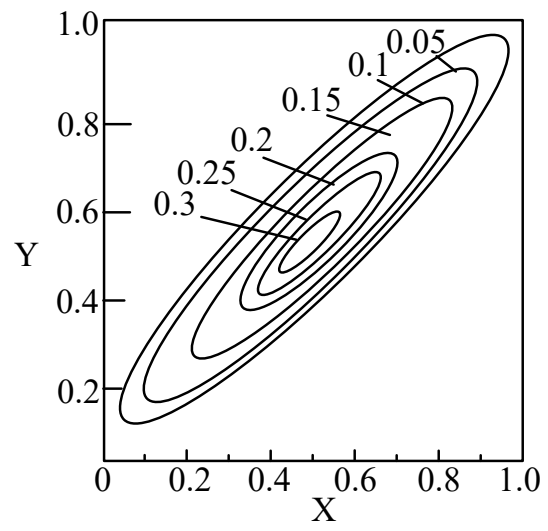

Fig. 2 Contour map of equation density

Selecting this equation as the best fitting equation can overcome the limitations of the research object. It is directly derived from the multidimensional normal distribution, which is easy to calculate. The symmetrical distribution does not have thick-tail characteristics, which is suitable for depicting symmetrical dependencies and no thick-tail Multidimensional risk factors for characteristics.

\section{EXPERIMENT ANALYSIS}

\section{A. Experimental data preparation}

In order to verify the degree of fit of the model designed in this paper to financial risks, a comparison experiment with traditional models is needed. Obtain the upper quantiles of different models respectively and compare them with standard values. The closer to the standard values, the better the model fits the corporate financial risk.

Select the Shanghai Composite Index and Shenzhen Component Index of some companies in a specific period of time as the original data. There are a total of 2331 trading day closing prices, and the logarithmic rate of return data has 2330 sample points. The asset portfolio under consideration contains two assets of equal weight $w_{1}=w_{2}=0.5$, and the returns of these two assets are completely positively correlated with the Shanghai and Shenzhen indices respectively. The return of the asset portfolio is regarded as a nonlinear differential equation of the returns of the two indices. Therefore, we can quantify the financial risk management of an enterprise by examining the returns on the Shanghai and Shenzhen Indexes.
By performing a normal JB hypothesis test on the empirical distribution, the returns of the two cities do not obey the normal distribution and have the characteristics of "spike tail". The $\mathrm{ADF}$ test on the return sequence is a 0 -order stationary random process. In order to characterize the thick-tailed features, a $\mathrm{t}$-distribution is used to describe the distribution of returns. The maximum likelihood method is used to estimate the degree of freedom of the t-distribution, and the logarithmic rate of freedom of the KLCI is 3.2718, which is approximately t-distribution. The maximum likelihood of the degrees of freedom of the logarithmic index of the deep index is 3. 2891, both of which approximately follow a t-distribution with a degree of freedom of 3 .

First estimate the parameters of the Normal-Copula and t-Copula equations, and calculate the value of the sample rank correlation coefficient Kendall $\tau, \tau=0.7473$, from:

$$
\rho=\sin \frac{\pi}{2 \tau}
$$

Can get $\rho=0.9222$. Since the two-dimensional t-function needs to estimate the degrees of freedom, the parameters of the selection equation need to be calculated. The results are shown in Table III.

Table. III Estimated values of equation parameters

\begin{tabular}{ccc}
\hline Function & Kendall $\tau$ & $\alpha$ \\
\hline Clayton & $\frac{\alpha}{\alpha+2}$ & 5.9144 \\
Gumbell & $1-\frac{1}{\alpha}$ & 3.9672 \\
Frank & $1-\frac{4\left[D_{1}(\alpha)-1\right]}{\alpha}$ & 13.9642 \\
\hline
\end{tabular}

After preparing the data, the experiment was started.

\section{B. Upper quantile solution results and analysis}

We need to evaluate the credit risk of corporate financial business of creditors, and we need to conduct a careful analysis of the evaluation results. Under normal circumstances, we generally use Logistic regression to establish credit evaluation models. However, the credit risk assessment of corporate financial services is different from the traditional credit assessment. As SMEs generally need funds urgently and most of them make loans for the first time, the bank's credit data for SME customers is incomplete, and a complete data storage and management system has not been established. The indicator can be divided into four grades of 10, 7, 4, 0 to score, then the score results are standardized, and finally the data is analyzed.

Using SPSS statistical software for principal component analysis, the cumulative contribution rate of the eigenvalues of the first ten principal components has reached $75.798 \%$. The 30 indicators in the indicator system can be expressed as Table IV. 


\begin{tabular}{|c|c|c|c|c|c|c|c|c|c|c|}
\hline & $F_{1}$ & $F_{2}$ & $F_{3}$ & $F_{4}$ & $F_{5}$ & $F_{6}$ & $F_{7}$ & $F_{8}$ & $F_{9}$ & $F_{10}$ \\
\hline $\mathrm{C} 1$ & 0.037 & 0.095 & 0.063 & 0.025 & 0.094 & 0.075 & 0.069 & 0.039 & 0.050 & 0.021 \\
\hline $\mathrm{C} 2$ & 0.050 & 0.004 & 0.048 & 0.036 & 0.085 & 0.055 & 0.035 & 0.020 & 0.002 & 0.092 \\
\hline $\mathrm{C} 3$ & 0.057 & 0.032 & 0.089 & 0.008 & 0.018 & 0.017 & 0.043 & 0.087 & 0.005 & 0.065 \\
\hline $\mathrm{C} 4$ & 0.083 & 0.083 & 0.095 & 0.076 & 0.006 & 0.096 & 0.001 & 0.002 & 0.050 & 0.044 \\
\hline C5 & 0.041 & 0.059 & 0.010 & 0.071 & 0.094 & 0.031 & 0.057 & 0.079 & 0.077 & 0.074 \\
\hline C6 & 0.053 & 0.021 & 0.016 & 0.009 & 0.067 & 0.093 & 0.002 & 0.078 & 0.050 & 0.067 \\
\hline C7 & 0.095 & 0.090 & 0.086 & 0.030 & 0.100 & 0.048 & 0.065 & 0.067 & 0.026 & 0.047 \\
\hline C8 & 0.041 & 0.036 & 0.081 & 0.081 & 0.097 & 0.020 & 0.054 & 0.098 & 0.003 & 0.056 \\
\hline C9 & 0.068 & 0.067 & 0.021 & 0.073 & 0.029 & 0.086 & 0.059 & 0.038 & 0.023 & 0.090 \\
\hline $\mathrm{C} 10$ & 0.091 & 0.023 & 0.011 & 0.015 & 0.040 & 0.007 & 0.000 & 0.006 & 0.094 & 0.093 \\
\hline $\mathrm{C} 11$ & 0.068 & 0.007 & 0.035 & 0.027 & 0.095 & 0.054 & 0.094 & 0.082 & 0.019 & 0.050 \\
\hline $\mathrm{C} 12$ & 0.013 & 0.084 & 0.080 & 0.044 & 0.003 & 0.056 & 0.076 & 0.005 & 0.088 & 0.035 \\
\hline $\mathrm{C} 13$ & 0.017 & 0.091 & 0.027 & 0.072 & 0.039 & 0.082 & 0.027 & 0.018 & 0.010 & 0.050 \\
\hline $\mathrm{C} 14$ & 0.058 & 0.073 & 0.077 & 0.028 & 0.053 & 0.004 & 0.040 & 0.065 & 0.018 & 0.089 \\
\hline $\mathrm{C} 15$ & 0.030 & 0.099 & 0.091 & 0.064 & 0.055 & 0.055 & 0.028 & 0.021 & 0.060 & 0.017 \\
\hline $\mathrm{C} 16$ & 0.085 & 0.088 & 0.095 & 0.029 & 0.076 & 0.095 & 0.075 & 0.050 & 0.089 & 0.066 \\
\hline $\mathrm{C} 17$ & 0.083 & 0.068 & 0.030 & 0.047 & 0.011 & 0.030 & 0.079 & 0.094 & 0.023 & 0.003 \\
\hline $\mathrm{C} 18$ & 0.078 & 0.080 & 0.048 & 0.092 & 0.023 & 0.076 & 0.001 & 0.080 & 0.053 & 0.024 \\
\hline C19 & 0.063 & 0.076 & 0.077 & 0.060 & 0.073 & 0.088 & 0.095 & 0.045 & 0.002 & 0.031 \\
\hline C20 & 0.095 & 0.054 & 0.087 & 0.049 & 0.075 & 0.022 & 0.061 & 0.044 & 0.058 & 0.038 \\
\hline $\mathrm{C} 21$ & 0.049 & 0.059 & 0.020 & 0.066 & 0.055 & 0.047 & 0.041 & 0.064 & 0.089 & 0.072 \\
\hline $\mathrm{C} 22$ & 0.086 & 0.094 & 0.027 & 0.071 & 0.041 & 0.026 & 0.065 & 0.057 & 0.017 & 0.048 \\
\hline C23 & 0.004 & 0.047 & 0.055 & 0.053 & 0.070 & 0.068 & 0.000 & 0.072 & 0.036 & 0.036 \\
\hline C24 & 0.069 & 0.067 & 0.057 & 0.002 & 0.061 & 0.078 & 0.030 & 0.566 & 0.069 & 0.091 \\
\hline $\mathrm{C} 25$ & 0.025 & 0.031 & 0.027 & 0.026 & 0.025 & 0.051 & 0.033 & 0.012 & 0.093 & 0.073 \\
\hline C26 & 0.039 & 0.016 & 0.041 & 0.047 & 0.036 & 0.087 & 0.013 & 0.080 & 0.053 & 0.016 \\
\hline C27 & 0.035 & 0.004 & 0.031 & 0.061 & 0.071 & 0.028 & 0.075 & 0.079 & 0.013 & 0.058 \\
\hline C28 & 0.081 & 0.094 & 0.003 & 0.082 & 0.052 & 0.085 & 0.038 & 0.029 & 0.027 & 0.016 \\
\hline C29 & 0.083 & 0.007 & 0.029 & 0.043 & 0.045 & 0.002 & 0.082 & 0.058 & 0.028 & 0.033 \\
\hline C30 & 0.090 & 0.041 & 0.026 & 0.080 & 0.033 & 0.099 & 0.036 & 0.090 & 0.065 & 0.087 \\
\hline
\end{tabular}

Finally, $F_{1}-F_{10}$ were selected as the final indicators for analysis. These 10 final indicators reflected the trustee's debt repayment ability, the quality of goods and the degree of Internet cooperation, the counterparty credit rating, profitability and industry environment, and the trustee's profitability. And development potential and so on of some companies. Using the model in this paper and the traditional model for analysis, 2350 random samples will be generated each time to obtain the required upper quantile. The two models are used to simulate 1 300 times respectively. The experimental results obtained are shown in Fig. 3.

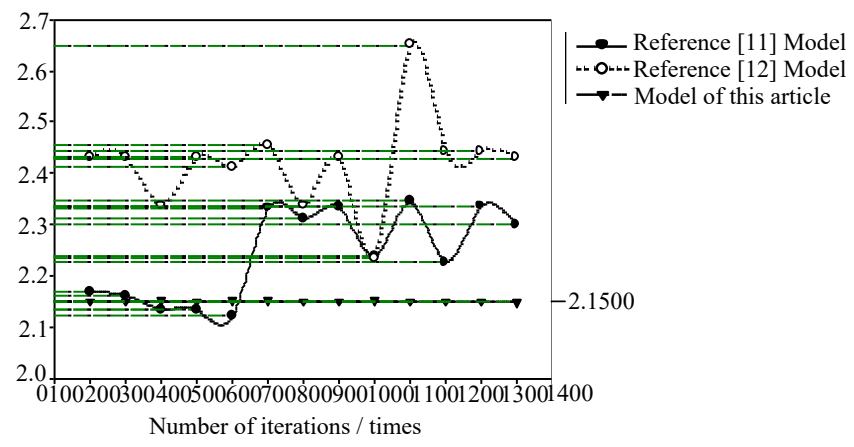

Fig. 3 Comparison of upper quantiles
According to the values in Fig. 3, the average value of the upper quantiles of 1300 simulations in the literature [11] model, the literature [12] model, and the design model can be obtained separately. When the number of experiments is 300 , the upper score of the model in [11] is 2.1342, the upper score of the model in [12] is 2.336, and the upper score of the model designed in this paper is 2.151. When the number of experiments is 1000 , the upper score of the model in [11] is 2.345 , the upper score of the model in [12] is 2.234, and the upper score of the model designed in this paper is 2.1502. The upper quantile of the method in this paper has been fluctuating around the standard value of 2.1500 , which indicates that the model designed in this paper is more accurate in finding the upper quantile, and also shows that the model in this paper has a higher degree of fit to corporate financial risks.

\section{Results and analysis of corporate financial risk} comprehensive evaluation

In the indicator system established in the text, different indicators always have different meanings, different amounts of information, different units of measurement, and different levels of quantity. Therefore, only when these indicators are unified into the same scale-the same unit of measurement, the same 
quantity level, and the same meaning of the evaluation information can be compared. Therefore, the adjusted data is quantified by the same method:

Metric value $=\frac{X_{i j}-\min \left(X_{i 1}, X_{i 2}, \ldots, X_{i 19}\right)}{\max \left(X_{i 1}, X_{i 2}, \ldots, X_{i 19}\right)-\min \left(X_{i 1}, X_{i 2}, \ldots, X_{i 19}\right)} \times 40+60$ were selected, and the [11] model and the design model in this paper were used to further verify the comprehensive evaluation of corporate financial risk. Taking the index data of three enterprises as training samples, the two models were trained, and then the risk assessment of these ten enterprises was carried out. The score results are shown in Table V.

After standardizing a number of indicatorsten companies

Table. V Comprehensive scoring results of the two models

\begin{tabular}{|c|c|c|c|c|}
\hline \multirow{2}{*}{ Enterprise encoding } & \multicolumn{2}{|c|}{ Reference [11] Model } & \multicolumn{2}{|c|}{ Paper model } \\
\hline & Comprehensive score & Ranking & Comprehensive score & Ranking \\
\hline 001 & 84.1354 & 4 & 60.7663 & 10 \\
\hline 002 & 70.8789 & 6 & 69.2424 & 6 \\
\hline 003 & 62.1754 & 9 & 70.9343 & 4 \\
\hline 004 & 81.9647 & 5 & 66.1273 & 8 \\
\hline 005 & 88.6240 & 2 & 87.8462 & 1 \\
\hline 006 & 69.0441 & 7 & 78.5270 & 3 \\
\hline 007 & 90.5478 & 1 & 69.5990 & 5 \\
\hline 008 & 68.1744 & 8 & 61.7952 & 9 \\
\hline 009 & 62.1343 & 10 & 66.9701 & 7 \\
\hline 010 & 87.1424 & 3 & 82.4237 & 2 \\
\hline
\end{tabular}

Make a preliminary statistical analysis of the comprehensive score results, the score results of each factor can be obtained as shown in Fig. 4.

\begin{tabular}{|c|c|}
\hline $\mathrm{N}$ & 10 \\
\hline Missing & 0 \\
\hline Mean & 78.3749 \\
\hline & 5 \\
\hline Median & 81.9647 \\
\hline & 0 \\
\hline Skewness & -.872 \\
\hline Std.Error of Skewness & .481 \\
\hline Kurtosis & 1.3362 \\
\hline Std.Error of Kurtosis & .789 \\
\hline Minimum & 62.1343 \\
\hline Maximum & 90.5478 \\
\hline
\end{tabular}

(a) Analysis of reference

[11] model results

\begin{tabular}{|lr|}
\hline $\mathrm{N}$ & $\begin{array}{r}\text { Valid } \\
\text { Missing }\end{array}$ \\
Mean & \\
& 72.4672 \\
& 5 \\
Median & 69.5990 \\
& 0 \\
Skewness & -.731 \\
Std.Error of Skewness & .345 \\
Kurtosis & 1.975 \\
Std.Error of Kurtosis & .644 \\
Minimum & 60.7663 \\
Maximum & 87.8462 \\
\hline
\end{tabular}

(b) Analysis of model results in this paper
Fig. 4 Statistical analysis of comprehensive scores

Among the 10 companies selected, the two models were used to score and rank them, and the results obtained were very different. In order to judge the accuracy of the two models, it is necessary to understand the real situation of the 10 companies. Take Company 005 as an example, the company's shares were listed on the Shanghai Stock Exchange in May 2018 and have been profitable for three consecutive years. Therefore, in 2017, the company was in an optimal financial situation, with sufficient capital flows and various Stakeholder relationships are handled properly. Senior management is highly motivated and has relatively low risk. The company's earnings per share, net profit growth rate, cash flow interest guarantee rate, income tax rate, etc. all show good values. Secondly, the average and median scores of corporate comprehensive scores are quite close, and Skewness is -0.731 . When the value is positive, the probability density function is skewed to the right, and the negative value is skewed to the left. When it is greater than 3, the distribution is more convex than the standard. Normal distribution, less than 3 means less than standard normal distribution. Therefore, the risk levels of different enterprises are relatively concentrated distributed on both sides of the industry average risk level. It can be shown that the model evaluation results designed in this paper are more in line with the actual situation, and also validate the validity of the quantitative model of enterprise financial risk management based on nonlinear differential equations.

\section{CONCLUSION}

Based on Copula's nonlinear differential equations, this paper designs a quantitative model of corporate financial risk management. The following conclusions were reached through experiments:

(1) The upper quantile of the design model is more accurate, and the degree of fit for corporate financial risk is higher. When the number of experiments is 1000 , the upper score of the design model is 2.1502 .

(2) The average value of the comprehensive score of the designed model is close to the median, the capital flow of the company is sufficient, the relationships between the various stakeholders of the company are properly handled, and the risks are relatively small. The model evaluation results designed in this paper are more in line with the actual situation.

In summary, the design model has better corporate financial risk management effects. According to the above results, the model designed in this paper can be applied to the financial risk assessment of enterprises, carry out financial early warning, comprehensively consider the hidden risks of each index, and formulate corresponding preventive measures, so as to better provide more efficient support for decision makers to formulate company management and operation strategies.

\section{References}

[1] J.J. Zhang, "Further results on transcendental meromorphic solutions of some certain types of nonlinear differential equations," Acta Mathematica Sinica, no. 4, pp. 529-540, 2018. 
[2] F. Yao, "Research on the evaluation of enterprise financial risk management-based on fuzzy comprehensive evaluation method," Journal of Henan Institute of Technology: Social Science Edition, vol. 35, no. 03, pp. $12-16,2020$.

[3] J.G. Zhang, F. Chen, and B. Wang, "Research on financial risk early warning of SVM manufacturing company based on PSO optimization," Friends of Accounting, no. 14, pp. 52-56, 2017.

[4] Y.D. Zhou, "The construction and application of AHP risk assessment model in Xinjihua Group," Finance and Accounting, no. 19, pp. 26-28, 2020.

[5] P.G. Wang, K.Y. Yang, and J.H. Qin, "Further result on convergence for a class of nonlinear integro-differential equations with initial value problems," Journal of Hebei University (Natural Science Edition), vol. 038, no. 005, pp. 449-453, 2018.

[6] S.Y. Wang, and Y. Li, "Solvability of nonlinear second-order boundary value problems with nonlinearities which cross the resonance points," Journal of Shandong University (Natural Science), vol. 53, no. 6, pp. 53-56+63, 2018.

[7] Y.T. Zeng, and J.W. Zhang, "Initial-boundary value problems for a coupled nonlinear partial differential equations with memory term," Mathematics in Practice and Theory, vol. 048, no. 10, pp. 230-237, 2018.

[8] J. Xing, and L.Y. Shi, "Application of quantitative model of enterprise risk management in petrochemical SOEs," Petroleum and Petrochemical Today, no. 5, pp. 7-12, 2019.

[9] Q.L. Tan, Y.L. Zhang, G.M. Chen, and Y.Z. Wu, "Quantitative risk assessment approach to the natural gas field gathering and transportation with highly sulfur-content based on the multi-factor effects," Journal of Safety and Environment, no. 3, pp. 876-881. 2018.

[10]S. Zhang, Q. Tan, Y.P. Cai, and T. Zhang, "A multi-objective optimization model for agricultural water resources based on fuzzy optimal selection and credibility," South-to-North Water Transfers and Water Science and Technology, no. 3, pp. 79-85, 2018.

[11]C.N. Xing, "Commentary on multifractal models and their applications in financial risk management," Statistics and Information Forum, no. 3, pp. 50-54, 2019.

[12]H.W. Ning and X.Y. Tu, "Research on stock market risk features based on high-dimensional volatility network model," Statistical Research, no. 10, pp. 58-73, 2019.

[13] S.Z. Zhu and Y.H. Gu, "The teaching reform design of "financial risk management" curriculum based on the three-dimensional comprehensive evaluation system," Education Teaching Forum, no. 12, pp. 132-135, 2019.

[14] J.H. Shao, and Y. Chen, "Research of tax levy model of complex manufacturing industry based on input-output model," Journal of Lanzhou Institute of Technology, vol. 24, no. 06, pp. 95-97, 2017.

[15]Z.P. Deng, and Y.X. Li, "Existence of solutions for a class of periodic bourdary value problem of third-order nonlinear ordinary differential equations," Journal of Sichuan University (Natural Science Edition), no. 5, pp. 792-796, 2019.
[16] W. Cheng, and J.M. Liu, "Modeling and simulation of credit optimization evaluation of small and medium-sized enterprises by bank loans," Computer Simulation, vol. 34, no. 12, pp. 204-208, 2017.

[17]X.Z. Zhang, "A program design for fitting optimal linear and nonlinear functional equations," Crop Journal, no. 3, pp. 38-40, 1986.

Hui Yang, female, (1982-), associate professor, from Liaocheng, Shandong, associate professor of Department of Economic Management, Dongchang College of Liaocheng University, research direction: financial theory and policy.

Guixian Tian, male, (1975-), associate professor, from Liaocheng, Shandong, associate professor of Business School, Pingxiang University. (Pingxiang, Jiangxi 337000), Research Field: Entrepreneurship and Innovation

Yongchao Tao, male, (1975-), associate researcher, from Liaocheng, Shandong, associate researcher of the Institute of Marine Economics and Culture, Shandong Academy of Social Sciences. (Qingdao, Shandong). Research direction: marine economy.

\section{Contribution of individual authors to the creation of a scientific article (ghostwriting policy)}

Hui Yang and Guixian Tian contributed to conception and design of the study. Yongchao Tao organized the database and performed the statistical analysis. Hui Yang wrote the first draft of the manuscript. All authors contributed to manuscript revision, read, and approved the submitted version.

\section{Creative Commons Attribution License 4.0 (Attribution 4.0 International, CC BY 4.0)}

This article is published under the terms of the Creative Commons Attribution License 4.0

https://creativecommons.org/licenses/by/4.0/deed.en_US 